\title{
Optimization of chemical and instrumental parameters in hydride generation laser-induced breakdown spectrometry for the determination of arsenic, antimony, lead and germanium in aqueous samples
}

\author{
Semira Ünal Yeşiller, Şerife Yalçın* \\ Izmir Institute of Technology, Faculty of Science, Chemistry Department, 35430 Urla, Izmir, Turkey
}

\section{H I G H L I G H T S}

- Continuous flow hydride generation technique for LIBS detection of As, Sb, $\mathrm{Pb}$ and $\mathrm{Ge}$.

- Optimization of chemical and instrumental parameters in HG-LIBS.

- Quantitative determination of As, Sb, $\mathrm{Pb}$ and $\mathrm{Ge}$ in aqueous samples.

- Enhancements in LOD values compared to direct liquids analysis by LIBS.

- Investigation of the effect of carrier gas on LIBS signal strength.

\section{A R T I C L E I N F O}

\section{Article history:}

Received 20 November 2012

Received in revised form 4 February 2013

Accepted 7 February 2013

Available online 16 February 2013

\section{Keywords:}

Laser-induced breakdown spectroscopy

Hydride generation

Toxic elements

Detection limit
G R A P H I C A L A B S T R A C T

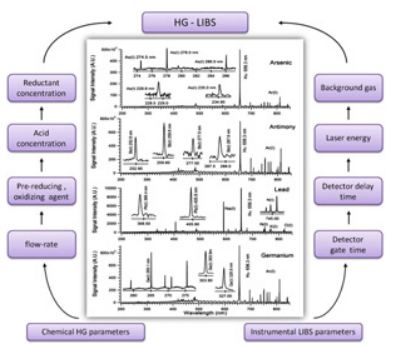

\begin{abstract}
A B S T R A C T
A laser induced breakdown spectrometry hyphenated with on-line continuous flow hydride generation sample introduction system, HG-LIBS, has been used for the determination of arsenic, antimony, lead and germanium in aqueous environments. Optimum chemical and instrumental parameters governing chemical hydride generation, laser plasma formation and detection were investigated for each element under argon and nitrogen atmosphere. Arsenic, antimony and germanium have presented strong enhancement in signal strength under argon atmosphere while lead has shown no sensitivity to ambient gas type. Detection limits of $1.1 \mathrm{mg} \mathrm{L}^{-1}, 1.0 \mathrm{mg} \mathrm{L}^{-1}, 1.3 \mathrm{mg} \mathrm{L}^{-1}$ and $0.2 \mathrm{mg} \mathrm{L}^{-1}$ were obtained for $\mathrm{As}, \mathrm{Sb}, \mathrm{Pb}$ and Ge, respectively. Up to 77 times enhancement in detection limit of $\mathrm{Pb}$ were obtained, compared to the result obtained from the direct analysis of liquids by LIBS. Applicability of the technique to real water samples was tested through spiking experiments and recoveries higher than $80 \%$ were obtained. Results demonstrate that, HG-LIBS approach is suitable for quantitative analysis of toxic elements and sufficiently fast for real time continuous monitoring in aqueous environments.
\end{abstract}

(c) 2013 Elsevier B.V. All rights reserved.

\section{Introduction}

Laser-induced breakdown spectroscopy (LIBS) [1,2] is an optical emission spectroscopic technique that uses a powerful pulsed laser source to produce plasma on a variety of sample types: solids,

\footnotetext{
* Corresponding author. Tel.: +90 232 7507624; fax: +90 2327507509 .

E-mail address: serifeyalcin@iyte.edu.tr (Ş. Yalçın).
}

liquids, gaseous and aerosols for a variety of applications: industrial, nuclear, geochemical, biomedical, military, space, planetary and environmental [3-11]. Time and space resolved analysis of characteristic atomic emission lines of the resultant plasma reveals information about the chemical content and the amount of the elements present. Some of the desirable properties like: its lack of need for sample preparation, multi-element capability, its speed and portability to the field make it extremely powerful analytical tool be used in environmental applications. 
Applications of LIBS on direct analysis of liquids are not as many as the ones on solids due to splashing, bubble and shockwave evolution problems which give rise to poor signal quality, reduced plasma emission and high quantification limits. Some approaches to overcome difficulties encountered in bulk liquid analysis include plasma formation: on flowing-jet liquid $[12,13]$, on the surface of the liquid [14,15], on single isolated droplets [16] and in cavitation bubbles [17]. Alternative to single-pulse LIBS experiments, doublepulse LIBS technique $[18,19]$ has been successfully applied for the analysis of aqueous [20] and underwater [21] samples in which the first laser pulse is used to create a gaseous atmosphere and the second pulse produce plasma with reduced background emission and longer lifetimes. Therefore, double pulse LIBS approach presents higher sensitivity over single pulse LIBS experiments and the analytical capability of the technique increases.

Electrospray ionization $[22,23]$ and proper nebulization techniques like pneumatic and ultrasonic nebulization also widely used to introduce liquid samples in the form of an aerosol $[24,25]$. Recently, analysis of liquids based on hydride generation sample introduction technique with laser-induced breakdown spectroscopic detection, HG-LIBS, for some of the hydride forming elements have been shown [27-29].

Hydride generation (HG) is a chemical derivatization process based on the formation of volatile hydrides from some of the elements of the periodic table in the presence of an acid and a strong reducing agent [26]. HG coupled with atomic spectrometric detection (HG-AAS, HG-ICP-OES, HG-AFS), is among the most common method for decades for its higher sensitivity and is widely used for quantification of $\mathrm{As}, \mathrm{Se}, \mathrm{Bi}, \mathrm{Ge}, \mathrm{Sb}, \mathrm{Sn}, \mathrm{Te}$ and $\mathrm{Pb}$ in liquid samples. However, there are a few studies based on coupling of the hydride generation system to laser-induced breakdown detection.

Singh et al. [27] have investigated the effect of the carrier gas ( $\mathrm{He}, \mathrm{Ar}$ ) and pressure on LIBS spectra of stannane $\left(\mathrm{SnH}_{4}\right)$ and arsine $\left(\mathrm{AsH}_{3}\right)$ in a batch type hydride generation system. Experiments were performed in an evacuated chamber. Work does not contain any quantitative data on the sensitivity of the technique; however, a decrease in the analyte signal due to depletion of the hydrides in the closed system has been mentioned.

In our previous work [28], development of a hydride generation laser-induced breakdown spectroscopic technique, HG-LIBS, in continuous flow mode was realized. The chemical and instrumental parameters of the system were systematically studied in order to achieve optimal conditions for the determination of $\operatorname{tin}(\mathrm{Sn})$ in aqueous environments. Several orders of magnitude enhancement in signal intensity was observed in comparison to direct liquid analysis by LIBS with a detection limit of $0.3 \mathrm{mg} \mathrm{L}^{-1}$ for Sn.

A more recent study in literature on continuous flow HGLIBS approach was performed by Simeonsson et al. [29], in which physical plasma parameters of arsine $\left(\mathrm{AsH}_{3}\right)$, stibine $\left(\mathrm{SbH}_{3}\right)$ and selenium hydride $\left(\mathrm{H}_{2} \mathrm{Se}\right)$ plasma were evaluated in $\mathrm{Ar}$ only and $\mathrm{Ar} / \mathrm{H}_{2}$ gas mixture. Plasma electron density determined through hydrogen emission measurements was found to vary from $4.5 \times 10^{17}$ to $8.3 \times 10^{15} \mathrm{~cm}^{-3}$ over time delays of $0.2-15 \mu \mathrm{s}$. Plasma temperatures determined through argon and arsenic emission measurements range from 8800 to $7700 \mathrm{~K}$ for Ar and from 8800 to $6500 \mathrm{~K}$ for As in HG-LIBS plasmas. Little difference in the excitation temperatures was observed. However, a significant reduction in the intensity and lifetime of Ar atomic emission lines in the HG-LIBS plasmas that appeared to be due to the presence of $\mathrm{H}_{2}$ was shown. Work does not include optimization of the chemical and instrumental LIBS parameters; however, limit of detection values of 0.7 , 0.2 and $0.6 \mathrm{mg} \mathrm{L}^{-1}$, were reported for arsenic, antimony and selenium, respectively. Results were obtained with a single wavelength detector, photomultiplier tube (PMT) and a boxcar averaging.

Here, in this paper a systematical analysis of chemical and instrumental parameters affecting HG-LIBS signal from arsine
$\left(\mathrm{AsH}_{3}\right)$, stibine $\left(\mathrm{SbH}_{3}\right)$, plumbane $\left(\mathrm{PbH}_{4}\right)$ and germane $\left(\mathrm{GeH}_{4}\right)$ plasma is presented, for the first time. The effect of differing ambient gas, argon and nitrogen, on the sensitivity of the HG-LIBS signal has been studied. Strong enhancement in signal strength of arsenic, antimony and germanium were observed under argon atmosphere. In order to investigate the causes of the much higher line intensity in Ar observed for three of the elements, a deeper study was carried out. The plasma temperature and electron number density were determined for both gases as a function of detector delay time. Calibration graphs were constructed, and detection limits were evaluated. The applicability of HG-LIBS technique for the determination of $\mathrm{As}, \mathrm{Sb}, \mathrm{Pb}$ and $\mathrm{Ge}$ in aqueous environments was tested by spiking each element in real water samples. Quantitative analysis of aqueous samples by HG-LIBS method was evaluated.

\section{Materials and methods}

\subsection{Experimental}

The experimental set-up for continuous flow hydride generation LIBS system [28], consists of a hydride generation, plasma formation and detection units.

In the hydride generation part, the acidified analyte and $\mathrm{NaBH}_{4}$ solutions are delivered to a three ways polytetrafluoroethylene (PTFE) connector (Supelco) by means of a four channel peristaltic pump (Longer Precision). U type gas-liquid separator (GLS) is used to separate gaseous hydrides from the solution. The drain of the waste solution is pumped from GLS with another peristaltic pump (ISMATEC, Germany). With a controlled flow of inert gas (Ar or $\mathrm{N}_{2}$ flowing continuously), hydrides are carried through the Nafion membrane dryer unit (Permapure, MD50) in order to remove the moisture content. Volatile hydrides produced in the hydride generation unit are then passed to the five-armed Teflon sample/plasma cell from the top where they interact with laser pulses at an angle of $90^{\circ}$ incidence with respect to incoming laser beam.

A Q-switched Nd:YAG laser (Spectra Physics, LAB 170-10) operating at the second harmonic $(532 \mathrm{~nm})$ wavelength with $10 \mathrm{~ns}$ pulse width and $10 \mathrm{~Hz}$ pulse repetition rate was used as a plasma source. The laser beam was focused by a $17.5 \mathrm{~cm}$ focal length plano-convex lens into the sample cell to form plasma from the gaseous hydrides. Plasma emission signal was collected and focused by using two $10.0 \mathrm{~cm}$ focal length plano-convex lenses onto the fiber optic cable (Ocean Optic, $600 \mu \mathrm{m}$ ). This fiber was then coupled to an echelle type spectrograph (ME5000, Andor Inc., $f=195 \mathrm{~mm}, 0.08 \mathrm{~nm}$ resolution), equipped with a gated, image intensified charge coupled detector, ICCD (iStar DH734, Andor Inc.). Wavelength calibration of the spectrograph was performed using a $\mathrm{Hg}-\mathrm{Ar}$ lamp. Detector gain was kept at a setting of 100 , and 10 shot accumulation spectra were used for most of the measurements.

\subsection{Reagents}

All reagents were of analytical grade or higher purity. Standard solutions of $\mathrm{As}, \mathrm{Sb}, \mathrm{Pb}$ and $\mathrm{Ge}$ were prepared daily from their $1000 \mathrm{mg} \mathrm{L}^{-1}$ stock solution (High-Purity Standards) through appropriate dilutions with ultra pure water. Sodium borohydride, $\mathrm{NaBH}_{4}$ solutions were prepared by dissolving its powder (Sigma-Aldrich) in dilute $\mathrm{NaOH}$ (Riedel-de Haën) for stabilization and used without filtration. $\mathrm{NaBH}_{4}$ solution was prepared in the presence of $1.0 \%(\mathrm{w} / \mathrm{v}) \mathrm{NaOH}$ for antimony, $0.2 \% \mathrm{NaOH}$ for arsenic and germanium, and $0.1 \% \mathrm{NaOH}$ for lead. Otherwise stated, acidified standards/samples and reductant solutions were delivered to the GLS at a flow rate of $2.5 \mathrm{~mL} \mathrm{~min}^{-1}$ and $5.0 \mathrm{~mL} \mathrm{~min}^{-1}$, respectively.

For antimony measurements, L-cysteine (Aldrich) was used as a pre-reducing agent and for lead, potassium hexacyanoferrate(III), 
$\mathrm{K}_{3}\left[\mathrm{Fe}(\mathrm{CN})_{6}\right]$ (Sigma-Aldrich) was used as an oxidizing agent. In the presence of $\mathrm{HCl}$ and $\mathrm{K}_{3}\left[\mathrm{Fe}(\mathrm{CN})_{6}\right]$, a highly toxic product, "HCN", is formed, therefore, this substance should be handled extremely carefully. The HG system is a closed system and a fume hood placed at the top of the system was used to provide effective ventilation.

River Water Reference Material for trace metals, SLRS-4 (NRC, Ottowa, Canada), tap water (İzmir-Urla Municipal Water Supply) and bottled spring water (Pınar, Aydın, Turkey) were used without dilution. For recovery experiments, due to the presence of undetectable concentrations of the target elements ( $\mathrm{As}, \mathrm{Sb}, \mathrm{Pb}, \mathrm{Ge})$, real water samples were spiked with known concentrations of a single element standards.

\section{Results and discussion}

In a HG-LIBS experiment, the type of the background/carrier gas and a number of instrumental and chemical variables need to be studied in order to maximize LIBS signal.

\subsection{Effect of carrier gas type on HG-LIBS signal}

The influence of the background gas on LIBS signal strength and the dynamics of the plasma plume expansion was vigorously studied in the past [29] and still is an active area in LIBS research. Experimental studies have shown that the nature and the pressure of background gas like $\mathrm{Ar}, \mathrm{He}, \mathrm{Air}, \mathrm{N}_{2}$, and $\mathrm{CO}_{2}$ have significant effects on the physical plasma parameters, temperature and electron density, and on the analyte signal enhancement [27,30-34]. In this work, to investigate the effect of carrier gas type on HGLIBS signal, continuous flow of argon and nitrogen gas was used to carry $\mathrm{As}, \mathrm{Sb}, \mathrm{Pb}$ and Ge hydrides from the gas-liquid separator into the plasma cell. Same analyte concentrations and identical instrumental and chemical conditions were used for recording a signal from the two different carrier gases.

Fig. 1(a)-(d) represents relative signal strength of each element under nitrogen and argon atmosphere. Solid lines represent signal in $\mathrm{Ar}$ and dotted lines represent signal in $\mathrm{N}_{2}$ atmosphere.

As can be seen from the figure that, arsenic signal at $278.0 \mathrm{~nm}$ could only be observed under argon atmosphere, however lead signal at $405.8 \mathrm{~nm}$, antimony signal at 259.8 and germanium signal at $265.1 \mathrm{~nm}$ were observed in the presence of both gases. Strong enhancement in $\mathrm{Ge}(\mathrm{I})$ and $\mathrm{Sb}(\mathrm{I})$ signal is observed under Ar atmosphere compared to nitrogen while $\mathrm{Pb}(\mathrm{I})$ signal intensity does not seem to be dependent on the type of the carrier gas. The same behavior was also observed for other emission lines of $\mathrm{As}(\mathrm{I}), \mathrm{Sb}(\mathrm{I})$ $\mathrm{Pb}(\mathrm{I})$ and $\mathrm{Ge}(\mathrm{I})$ within the full spectra. Therefore, optimization studies of arsenic, antimony and germanium were performed under argon environment while signal optimizations for lead were performed in the presence of nitrogen due to its lower cost.

Enhanced signal strength under Ar atmosphere is consistent with some literature work [35-37]. It has been reported that $\mathrm{Ar}$ gas provides higher signal intensity due to increased lifetime of $\mathrm{Ar}$ plasma and hence stable plasma temperatures and electron densities are obtained. The intensity enhancement of $\mathrm{C}$ and $\mathrm{H}$ lines in He plasma has also been reported by other groups [38,39]. In those studies, the enhancement mechanism due to the energy transfer from excited He or Ar atoms to the analyte atoms via Penning ionization was proposed.

In order to investigate the causes of the much higher line intensity observed in $\mathrm{Ar}$ atmosphere, electron density and temperature variation of HG-LIBS plasmas with respect to detector delay time were also evaluated. Plasma temperatures were determined from the Boltzmann equation [40] by using spectral emission intensities of neutral $\mathrm{Ge}(\mathrm{I})$ lines, based on the assumption that plasma is in
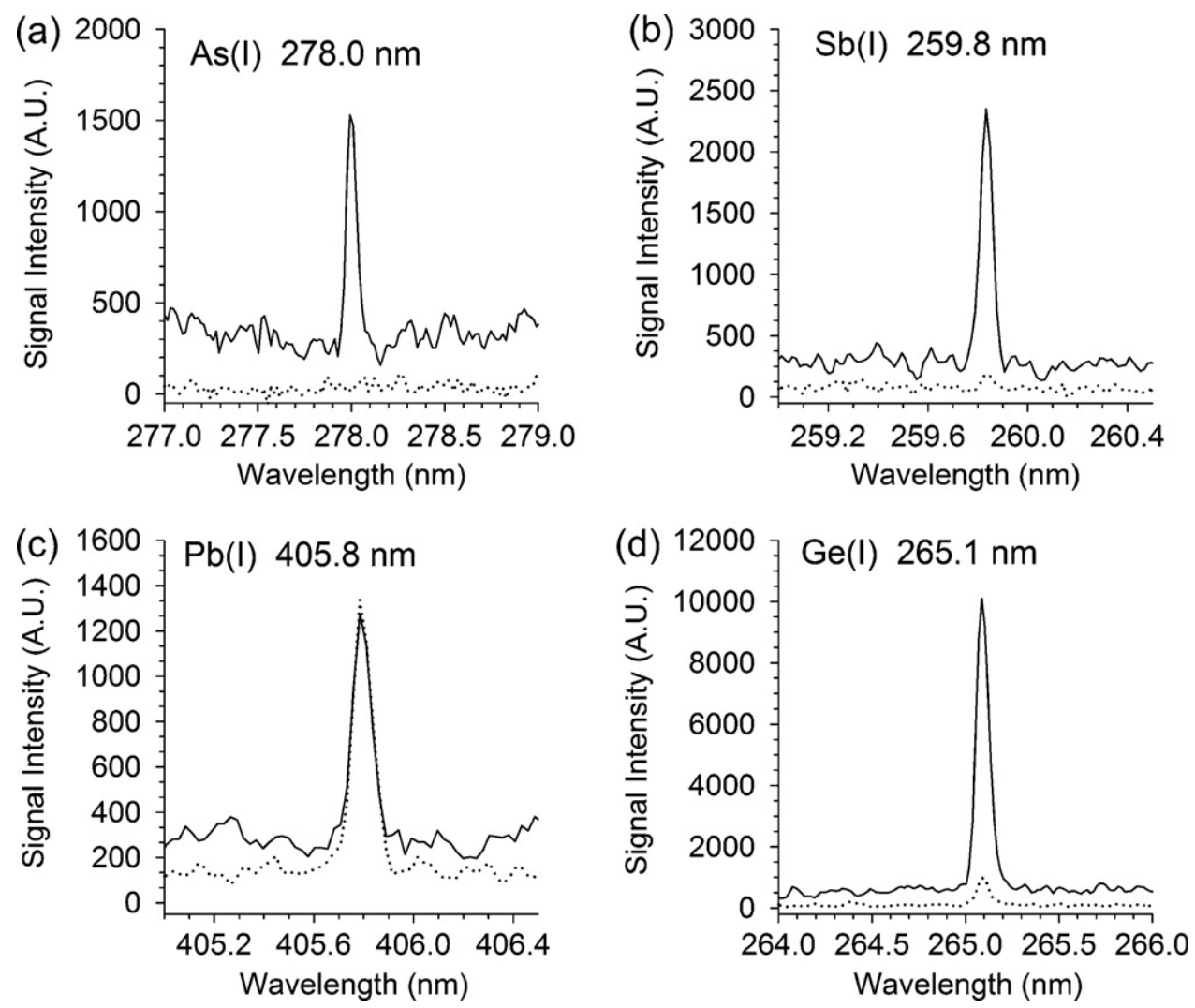

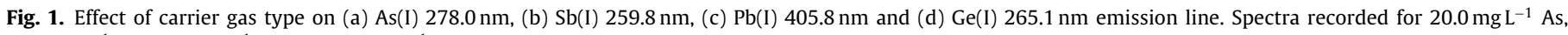
$40.0 \mathrm{mg} \mathrm{L}^{-1} \mathrm{Sb}, 20.0 \mathrm{mg} \mathrm{L}^{-1} \mathrm{~Pb}$ and $20.0 \mathrm{mg} \mathrm{L}^{-1} \mathrm{Ge}$. Solid lines represent signal under Ar and dotted lines represent signal under $\mathrm{N}_{2}$ atmosphere. 

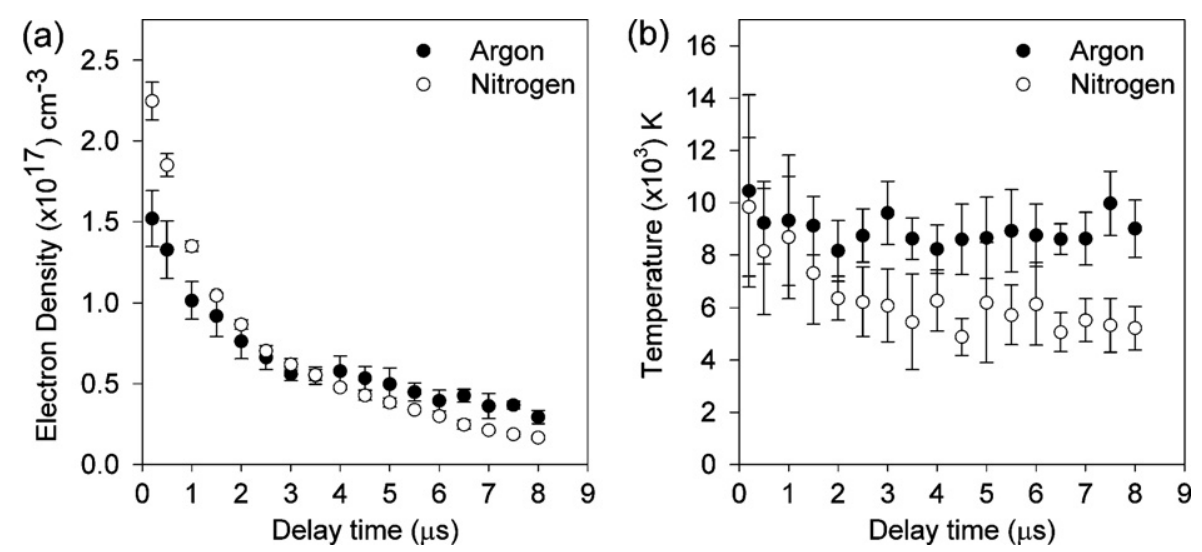

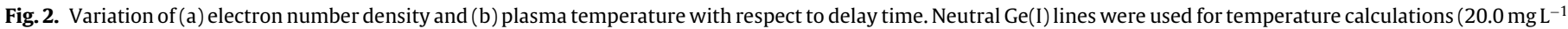
$\mathrm{Ge}$ in $1.0 \% \mathrm{HCl}, 0.2 \% \mathrm{NaBH}_{4}$ in $0.2 \% \mathrm{NaOH}, 126.0 \mathrm{~mL} \mathrm{~min}^{-1} \mathrm{Ar}_{\text {or }} \mathrm{N}_{2}, t_{\mathrm{g}}: 100 \mu \mathrm{s}$, LE: $100 \mathrm{~mJ}$ pulse $\left.{ }^{-1}, n=7\right)$.

local thermodynamic equilibrium (LTE). On the other hand, electron density values of the hydride plasmas were calculated from the Stark broadened profiles of neutral $\mathrm{H}(\mathrm{I})$ lines at $656.3 \mathrm{~nm}[40]$. Fig. 2(a) and (b) shows the temporal variation of electron number density and plasma temperature in the presence of argon and nitrogen as carrier gases. Generally, electron number density decreases drastically as the detector delay time increases, from $1.5 \times 10^{17}$ to $2.9 \times 10^{16}$ for Ar and from $2.2 \times 10^{17}$ to $1.6 \times 10^{16}$ for $\mathrm{N}_{2}$, due to ionelectron recombination processes. When the variation of plasma temperature in both argon and nitrogen atmosphere is considered, it has been found that Ar atmosphere has relatively higher temperatures than the ones in $\mathrm{N}_{2}$ atmosphere, especially at late delay times. Between $0.2 \mu \mathrm{s}$ and $8 \mu \mathrm{s}$ time interval, plasma temperature that ranges from $10500 \mathrm{~K}$ to $8500 \mathrm{~K}$ in argon environment and $9832 \mathrm{~K}$ to $5216 \mathrm{~K}$ in $\mathrm{N}_{2}$ environment were obtained. Also, the plasma temperature variation with respect to delay time in $\mathrm{Ar}$ is more stable than the one in $\mathrm{N}_{2}$ atmosphere.
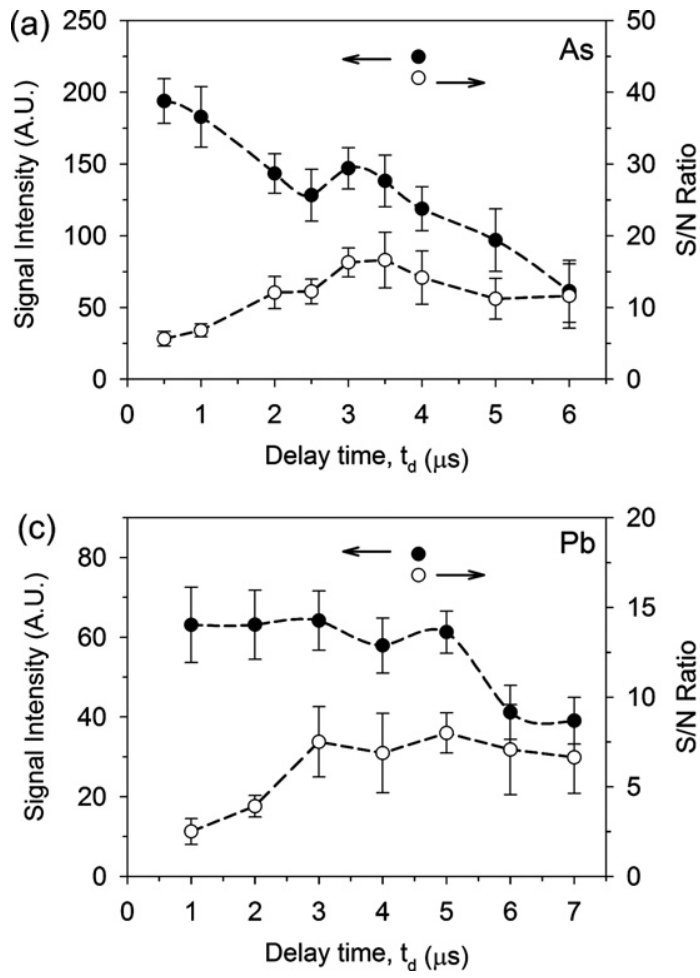

Results are consistent with the plasma temperatures presented by Simeonsson et al. through argon and arsenic line emission measurements [29]. The intensity enhancement in Ge emission lines, observed in this study, in the presence of Ar gas can be attributed to the Penning ionization process, in which, metastable states of Ar participate in the collision induced energy transfer process, as explained in the previous works by Sasaki et al. [37] and Lie et al. [39]. It may be proposed that; this secondary excitation of analyte atoms, Ge in this case, by metastable Ar atoms, in addition to initial laser pulse excitation, may lead to the state of sustained emission of analyte atoms in the HG-LIBS plasmas and hence the signal is enhanced.

\subsection{Optimization of instrumental parameters}

Laser type, laser wavelength, laser energy and detector timing parameters as delay and gate time are considered as some of the
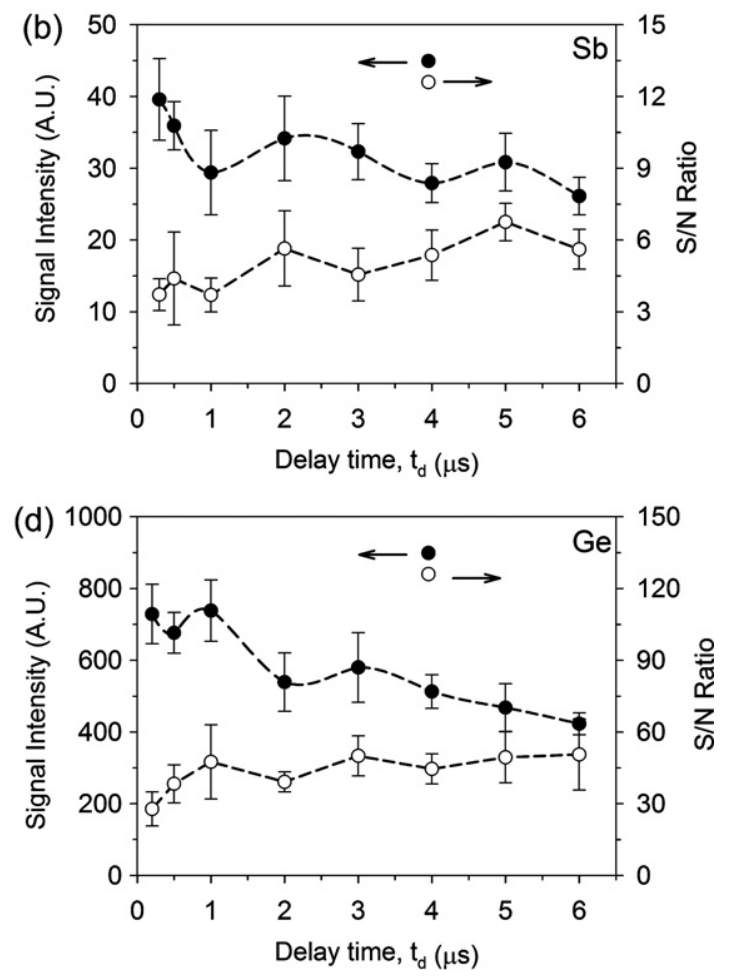

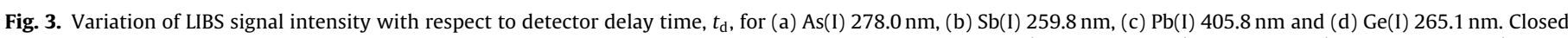
circles indicate relative signal intensity and open circles indicate $\mathrm{S} / \mathrm{N}$ ratio. Spectra was recorded for $100.0 \mathrm{mg} \mathrm{L}^{-1} \mathrm{As}_{10} 100.0 \mathrm{mg} \mathrm{L}^{-1} \mathrm{Sb}_{2} 20.0 \mathrm{mg} \mathrm{L}^{-1} \mathrm{~Pb}$ and $20.0 \mathrm{mg} \mathrm{L}^{-1} \mathrm{Ge}$ 
instrumental parameters in a LIBS experiment. In this study, the variation of LIBS signal strength with respect to laser pulse energy from a Nd:YAG laser at $532 \mathrm{~nm}$, and detector timing parameters were studied.

\subsubsection{Detector gating parameters and laser pulse energy}

Time resolution experiments were performed for optimization of detector gating parameters such as delay time, $t_{\mathrm{d}}$, and gate width, $t_{\mathrm{g}}$.

In order to investigate the effect of delay time on LIBS signal variation, plasma emission signals from chemically generated hydrides were recorded at various detector delay times with respect to the laser pulse. Fig. 3(a)-(d) represents the variation of neutral As(I) $278.0 \mathrm{~nm}, \mathrm{Sb}(\mathrm{I}) 259.8 \mathrm{~nm}, \mathrm{~Pb}(\mathrm{I}) 405.8 \mathrm{~nm}$ and $\mathrm{Ge}(\mathrm{I}) 265.1 \mathrm{~nm}$ line intensity with respect to delay time.

In general, at early times of the plasma, relative signal intensity is higher and decreases as delay time increases. However, due to the presence of higher level of background at early delay times, the signal to noise ratio $(\mathrm{S} / \mathrm{N})$ consideration would be more accurate for the determination of optimal delay time. Therefore, the delay time at the maximum $\mathrm{S} / \mathrm{N}$ was selected as optimum. The $\mathrm{S} / \mathrm{N}$ data given in Fig. 3 were presented with empty circles and scaled on the right side of each graph, for every element under consideration. Here, signal is defined as the average of net peak height from 5 sequential measurements and the noise is defined as three times the standard deviation of the background in a region near the signal for the same number of measurements. Optimum $t_{\mathrm{d}}$ value for $\mathrm{As}, \mathrm{Sb}, \mathrm{Pb}$ and $\mathrm{Ge}$ was determined as $3.0 \mu \mathrm{s}, 2.0 \mu \mathrm{s}, 5 \mu \mathrm{s}$ and $1 \mu \mathrm{s}$, respectively.

Variation of HG-LIBS signal with respect to detector gate width and laser pulse energy is given in Fig. 4(a) and (b), respectively. Here, compared to $\mathrm{Sb}$, As and $\mathrm{Pb}$ signal, relatively higher signal strength is observed from the Ge lines, therefore, in order to show them all in the same figure, left axis was used for representing $\mathrm{Ge}$ line intensity while right axis was used for the other three elements. Similarly, the top axis of Fig. 4(a) corresponds to detector gating times for the element of arsenic. For arsenic, highest signal intensity was obtained with $750 \mu$ s gate width. Varying gating time from $10 \mu$ s to $50 \mu$ s resulted in a sharp increase in Sb signal however, beyond this value no noticeable change in signal intensity was observed. As seen from Fig. 4(a), gating time had no serious effect on $\mathrm{Pb}$ signal. In the case of germanium, changing gate width from $25 \mu \mathrm{s}$ to $50 \mu \mathrm{s}$ caused the signal to increase two times, while at $100 \mu \mathrm{s}$, a slight increase was observed. Thus, optimum gate widths were determined as $750 \mu$ s for arsenic, $50 \mu \mathrm{s}$ for antimony and $100 \mu \mathrm{s}$ for lead and germanium.

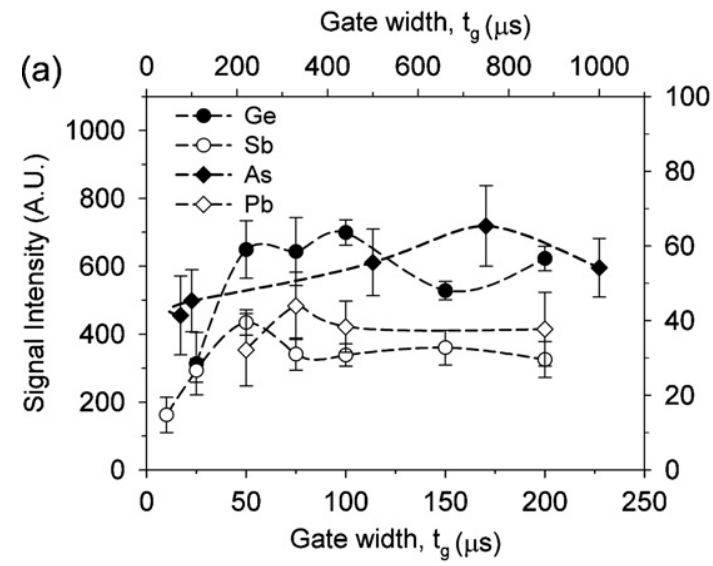

Laser pulse energy is another crucial instrumental variable needs to be optimized in laser induced plasmas. In order to determine optimum laser energy for LIBS measurements, plasma emission was recorded as a function of laser energy at optimum detector gating parameters. Data presented in Fig. 4(b) are for five replicate measurements and error bars on the graphs were obtained from the standard deviation of the signal. Generally, increasing laser pulse energy increases the emission intensity for all elements studied. After $100 \mathrm{~mJ}$ pulse ${ }^{-1}$ laser energy, deviation from the linearity that could be attributed to the plasma shielding effect was observed for As, Sb, and Ge.

\subsubsection{Representative LIBS spectra under optimum experimental conditions}

Representative LIBS spectra from arsine, stibine, plumbane, and germane plasma obtained under optimal instrumental and chemical conditions between 200 and $850 \mathrm{~nm}$ spectral interval are given in Fig. 5(a)-(d). For each element studied, several neutral atomic emission lines could be observed and insets of each figure detailed spectra representing the lines of interest is presented. In Fig. 5(a), neutral As(I) lines at $228.8 \mathrm{~nm}, 235.0 \mathrm{~nm}, 274.5 \mathrm{~nm}, 278.0 \mathrm{~nm}$, and $286.0 \mathrm{~nm}$ are given. Representative spectrum from $\mathrm{SbH}_{3}$ given in Fig. 5(b), shows four neutral emission lines of $\mathrm{Sb}(\mathrm{I})$ at $252.8 \mathrm{~nm}$, $259.8 \mathrm{~nm}, 277.0 \mathrm{~nm}$, and $287.8 \mathrm{~nm}$. Three neutral emission lines of $\mathrm{Pb}(\mathrm{I})$ at $280.2 \mathrm{~nm}, 368.4$ and $405.8 \mathrm{~nm}$ were given in Fig. 5(c). Besides, a well resolved sodium doublet emission at 589.0 and $589.6 \mathrm{~nm}$ and potassium doublet at $766.5 \mathrm{~nm}$ and $769.9 \mathrm{~nm}$ were also observed. Presence of these lines in spectra indicates $\mathrm{Na}$ and $\mathrm{K}$ transport from GLS to the Teflon plasma cell along with the gaseous hydrides. All spectra are strongly dominated by the neutral hydrogen line, $H_{\alpha}$, at $656.3 \mathrm{~nm}$ which is produced from the dissociation of the metal hydrides under intense laser beam. Some argon emission lines in the far end of the visible region are also observed. Fig. 5(d) include seven neutral emission lines of germanium at $259.2 \mathrm{~nm}$, $265.1 \mathrm{~nm}, 269.1 \mathrm{~nm}, 270.9 \mathrm{~nm}, 275.4 \mathrm{~nm}, 303.9 \mathrm{~nm}$ and $326.9 \mathrm{~nm}$, which makes germanium a strong candidate to be used as a temperature sensor.

Quantitative measurements of $\mathrm{As}, \mathrm{Sb}, \mathrm{Pb}$ and $\mathrm{Ge}$ were performed at their most sensitive wavelengths of $278.0 \mathrm{~nm}, 259.8 \mathrm{~nm}$, $405.8 \mathrm{~nm}$ and $265.1 \mathrm{~nm}$, respectively.

\subsection{Optimization of chemical parameters}

It is well known that generation and transportation of volatile hydrides is very much dependent on various chemical parameters: such as acid and reductant concentration, presence of

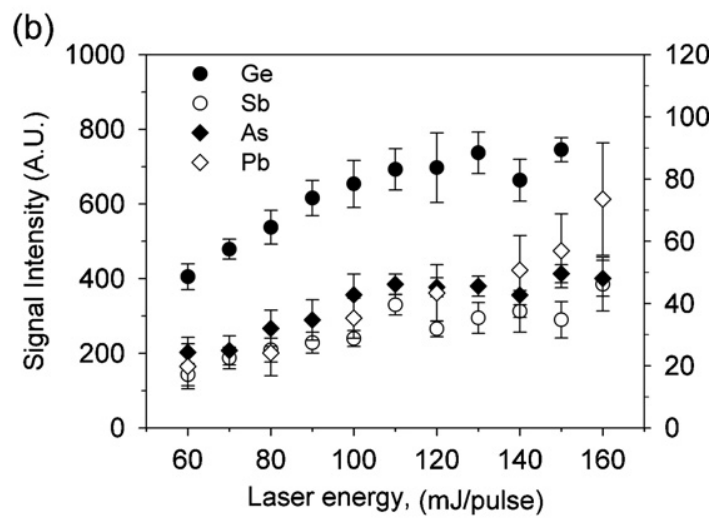

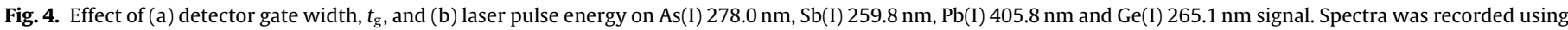
$20.0 \mathrm{mg} \mathrm{L}^{-1}$ As, $100.0 \mathrm{mg} \mathrm{L}^{-1} \mathrm{Sb}, 20.0 \mathrm{mg} \mathrm{L}^{-1} \mathrm{~Pb}$ and $20.0 \mathrm{mg} \mathrm{L}^{-1} \mathrm{Ge}$. 

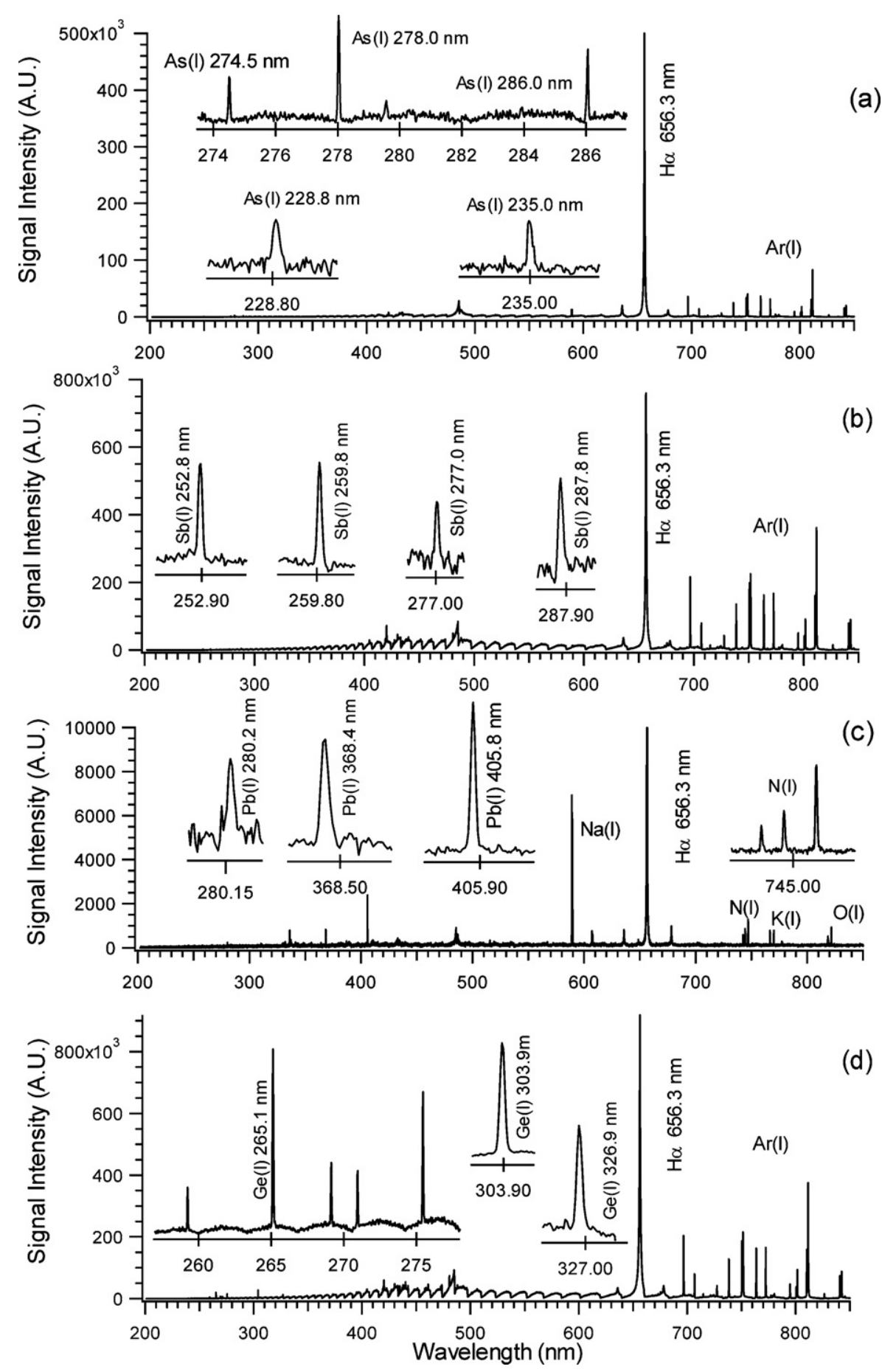

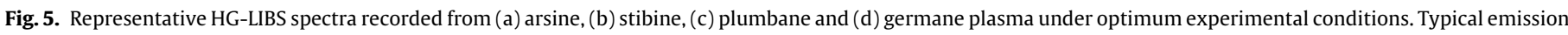
profiles of each element are presented inside each spectrum, in enlarged scale.

oxidizing/pre-reducing agent, sample and carrier gas flow rate. For this purpose, not only instrumental but also chemical parameters were also systematically investigated for each element to maximize HG-LIBS signal.

\subsubsection{Effect of pre-reducing agent, L-cysteine, on Sb HG-LIBS} signal

Oxidation of $\mathrm{Sb}(3+)$ to $\mathrm{Sb}(5+)$ might take place under acidic conditions, and pentavalent form of antimony presents significantly lower sensitivity than its trivalent form, during its detection from the chemically generated hydrides. L-Cysteine is known to have an effective pre-reduction capacity $[41,42]$ and widely used in HG systems for reducing antimony into its lower oxidation state before detection.

In this study, due to low LIBS signal intensity obtained from Sb hydrides even with $100.0 \mathrm{mg} \mathrm{L}^{-1} \mathrm{Sb}^{3+}$ solution concentrations, the effect of adding pre-reducing agent on LIBS signal strength was investigated. For this purpose $\mathrm{Sb}(\mathrm{I})$ signal at $259.8 \mathrm{~nm}$ were recorded in the presence of selected L-cysteine concentrations, between $0.2 \%$ and $5.0 \%(\mathrm{w} / \mathrm{v})$, under optimum acid and reducing agent concentrations $\left(2.0 \% \mathrm{HCl}\right.$ and $1.0 \% \mathrm{NaBH}_{4}$ in $\left.1.0 \% \mathrm{NaOH}\right)$. The effect of adding pre-reducing agent on LIBS signal strength of $\mathrm{Sb}(\mathrm{I})$ 

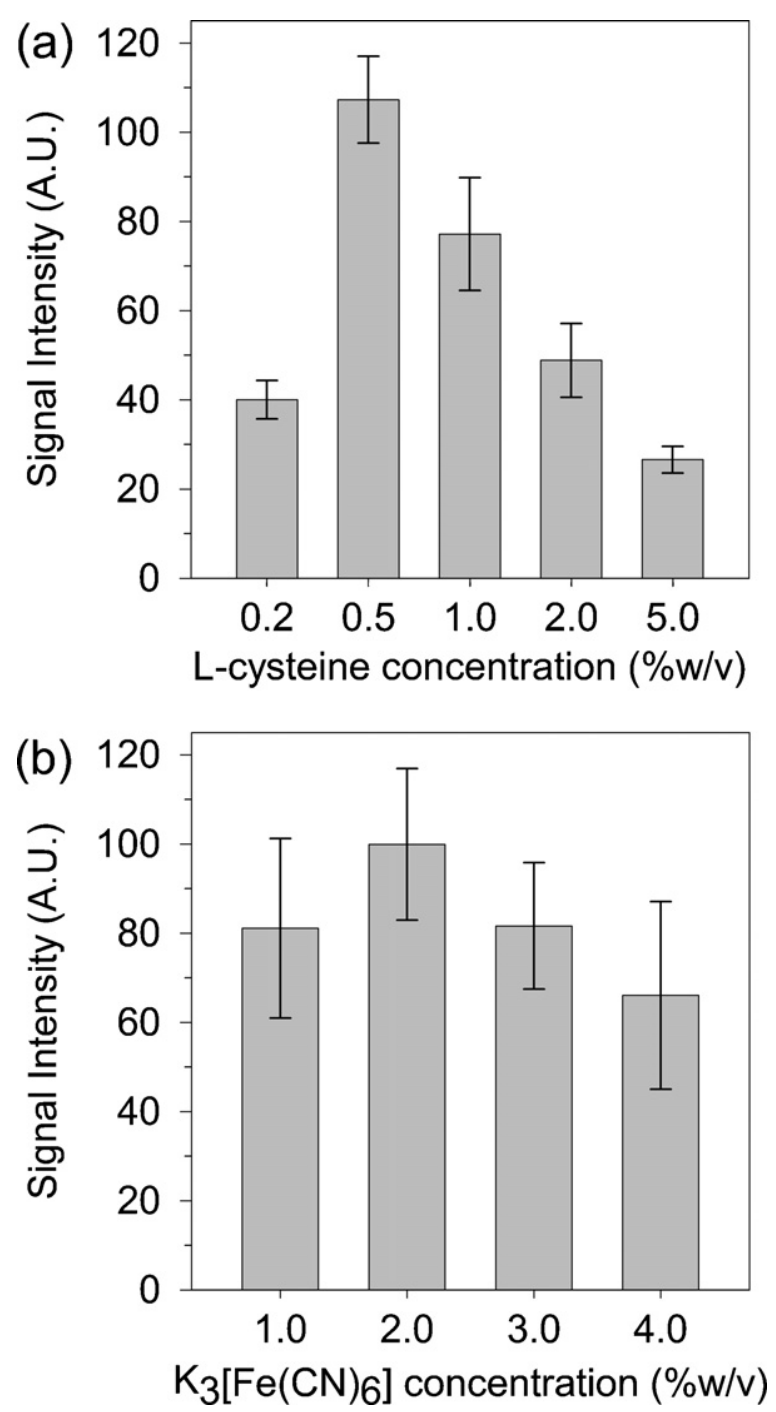

Fig. 6. (a) Variation in $\mathrm{Sb}(\mathrm{I})$ signal at $259.8 \mathrm{~nm}$ with respect to L-cysteine concentration. $100.0 \mathrm{mg} \mathrm{L}^{-1} \mathrm{Sb}(+3)$ in $2.0 \% \mathrm{HCl}, 1.0 \% \mathrm{NaBH}_{4}$ in $1.0 \% \mathrm{NaOH}, t_{\mathrm{d}}: 2 \mu \mathrm{s}, t_{\mathrm{g}}$ : $50 \mu \mathrm{s}$, carrier gas: $160 \mathrm{~mL} \mathrm{~min}^{-1} \mathrm{Ar}$, and laser energy: $100 \mathrm{~mJ} \mathrm{pulse}^{-1}$ were used. (b) Effect of oxidizing agent concentration on $\mathrm{Pb}(\mathrm{I})$ signal intensity at $405.8 \mathrm{~nm}$. $100.0 \mathrm{mg} \mathrm{L}^{-1} \mathrm{~Pb}$ in $2.0 \% \mathrm{HCl}, 1.0 \% \mathrm{NaBH}_{4}$ in $0.1 \% \mathrm{NaOH}, t_{\mathrm{d}}: 5 \mu \mathrm{s}, t_{\mathrm{g}}: 100 \mu \mathrm{s}$, carrier gas: $155 \mathrm{~mL} \mathrm{~min}^{-1} \mathrm{~N}_{2}$, and LE: $150 \mathrm{~mJ}$ pulse $\mathrm{e}^{-1}$ were used.

is given in Fig. 6(a). More than two times enhancement in $\mathrm{Sb}(\mathrm{I})$ signal was obtained by increasing L-cysteine concentration from $0.2 \%$ to $0.5 \%$. However, between $1.0 \%$ and $5.0 \%$ L-cysteine concentration, $\mathrm{Sb}$ signal started to decline, linearly. Therefore, optimum L-cysteine concentration was selected as $0.5 \%(\mathrm{w} / \mathrm{v})$ and used accordingly for $\mathrm{Sb}$ analysis by keeping the rest of the parameters constant.

\subsubsection{Effect of oxidizing agent, $\mathrm{K}_{3}\left[\mathrm{Fe}(\mathrm{CN})_{6}\right]$, on Pb HG-LIBS signal}

Lead determination by hydride generation is known to be challenging due to the low yield and instability of plumbane. Several studies in the literature have shown that the reaction rate and signal sensitivity could be increased by the addition of an oxidizing agent: potassium hexacyanoferrate(III), $\mathrm{K}_{3}\left[\mathrm{Fe}(\mathrm{CN})_{6}\right]$ [43-45]. In order to increase the stability of lead hydrides, $\mathrm{K}_{3}\left[\mathrm{Fe}(\mathrm{CN})_{6}\right]$ was also used as an oxidizing agent in this study. Optimum oxidizing agent concentration was investigated by recording HG-LIBS signal from $20.0 \mathrm{mg} \mathrm{L}^{-1} \mathrm{~Pb}$ solutions in the presence of $1.0 \%, 2.0 \%$, $3.0 \%$, and $4.0 \%(\mathrm{w} / \mathrm{v})$ potassium hexacyanoferrate(III). As is shown in Fig. 6(b), the highest $\mathrm{Pb}(\mathrm{I})$ signal at $405.8 \mathrm{~nm}$ was obtained when $2.0 \% \mathrm{~K}_{3}\left[\mathrm{Fe}(\mathrm{CN})_{6}\right]$ was used.
Another problem that has been faced during plumbane generation, due to a vigorous reaction between acid and $\mathrm{NaBH}_{4}$, was the excessive foaming and aerosol carry over from GLS to membrane dryer. These foamy aerosols were adsorbed on the upper-inner walls of the GLS and inside the Teflon tubing that connects the GLS to membrane drying unit. This, in turn, reduced the reproducibility of the signal. In order to reduce aerosol carry over, data collection was performed while the carrier gas $\mathrm{N}_{2}$ blowing above the liquid level instead of continuous bubbling inside.

\subsubsection{Effect of acid concentration}

The type and concentration of acid plays an essential role in hydride generation reactions. Various types of acids (such as hydrochloric acid, nitric acid, sulfuric acid, tartaric acid, acetic acid and hydrofluoric acid) may be used. Among these the most widely used one is $\mathrm{HCl}$. In this study, analyte solutions were prepared in the range of $0.1-3.0 \%(\mathrm{v} / \mathrm{v}) \mathrm{HCl}$ concentrations. Use of acid concentration higher than $5.0 \%(\mathrm{v} / \mathrm{v})$ resulted in alteration in the plasma position due to production of excess hydrogen gas and could be recognized from the suppression of the analyte signal and the decrease in the powerful breakdown sound.

The effect of acid concentration on HG-LIBS signal strength for all four elements under study is presented in Fig. 7(a). Here, due to the higher signal intensity of Ge lines observed, compared to Sb, As and $\mathrm{Pb}$ signal, left axis of the figure was used for $\mathrm{Ge}$ line intensity while right axis was used for the representation of the rest. Each element behaves differently with changing acid concentrations. Neutral As(I) signal at $278.0 \mathrm{~nm}$ was not affected significantly by increasing acid concentration from $0.2 \%$ to $1.0 \%$ while after this concentration signal starts to decrease. Neutral Sb(I) LIBS signal at $259.8 \mathrm{~nm}$, obtained from $40.0 \mathrm{mg} \mathrm{L}^{-1} \mathrm{Sb}^{3+}$ in the presence of $0.5 \%$ L-cysteine solution, increases from $1.0 \%$ to $2.0 \%$ acid concentration and beyond this value the signal starts to decrease again. As it can be seen from the figure that neutral $\mathrm{Pb}(\mathrm{I})$ signal at $405.8 \mathrm{~nm}$ presents maximum sensitivity at $2.5 \% \mathrm{HCl}$ concentration. Increasing $\mathrm{HCl}$ concentration from $0.2 \%$ to $1.0 \%$ results in a sharp increase in $\mathrm{Ge}(\mathrm{I})$ $265.1 \mathrm{~nm}$ signal and after this point, signal decreases drastically. Optimum acid concentrations for the analysis of $\mathrm{As}, \mathrm{Sb}, \mathrm{Pb}$ and $\mathrm{Ge}$ were selected as $1.0 \%, 2.0 \%, 2.5 \%$ and $1.0 \%$, respectively, throughout the measurements. During acid optimization studies, $\mathrm{NaBH}_{4}$ concentration was kept as $2.0 \%$ for arsenic and $1.0 \%$ for antimony, lead and germanium.

\subsubsection{Effect of reductant, $\mathrm{NaBH}_{4}$ concentration}

Optimum $\mathrm{NaBH}_{4}$ concentration was also investigated in order to achieve maximum response from arsenic, antimony, lead and germanium hydrides by HG-LIBS. Solutions prepared in differing $\mathrm{NaBH}_{4}$ concentrations were reacted with analyte solutions prepared in dilute $\mathrm{HCl}$. Resulting volatile hydrides purged with a flow of carrier gas and plasma emission signal were collected under optimum instrumental parameters. Signal strength variation with respect to $\mathrm{NaBH}_{4}$ concentration for each element under consideration is given in Fig. 7(b). Left axis of the figure was used for Ge line intensity, and right axis was used for the representation of the $\mathrm{Sb}$, As and $\mathrm{Pb}$ signal, due to relatively higher signal intensity of $\mathrm{Ge}$ lines.

Increasing $\mathrm{NaBH}_{4}$ concentration from $0.05 \%$ to $0.5 \%$ increases arsenic signal two times. At higher concentrations signal decreases. Thus, $0.5 \% \mathrm{NaBH}_{4}$ was determined to be an optimal reductant concentration for arsenic. $\mathrm{Sb}(\mathrm{I})$ signal strength at $259.8 \mathrm{~nm}$ presents a sharp increase when $\mathrm{NaBH}_{4}$ concentration was increased from $0.1 \%$ to $1.0 \%$, then gradually decreases until $2.5 \%$ reductant concentrations. $1.0 \% \mathrm{NaBH}_{4}$ concentration was selected as an optimal reductant concentration for $\mathrm{Sb}$.

Increasing reductant concentration from $0.5 \%$ to $1.0 \%$ increases $\mathrm{Pb}(\mathrm{I})$ signal at $405.8 \mathrm{~nm}$ and at higher concentrations signal 

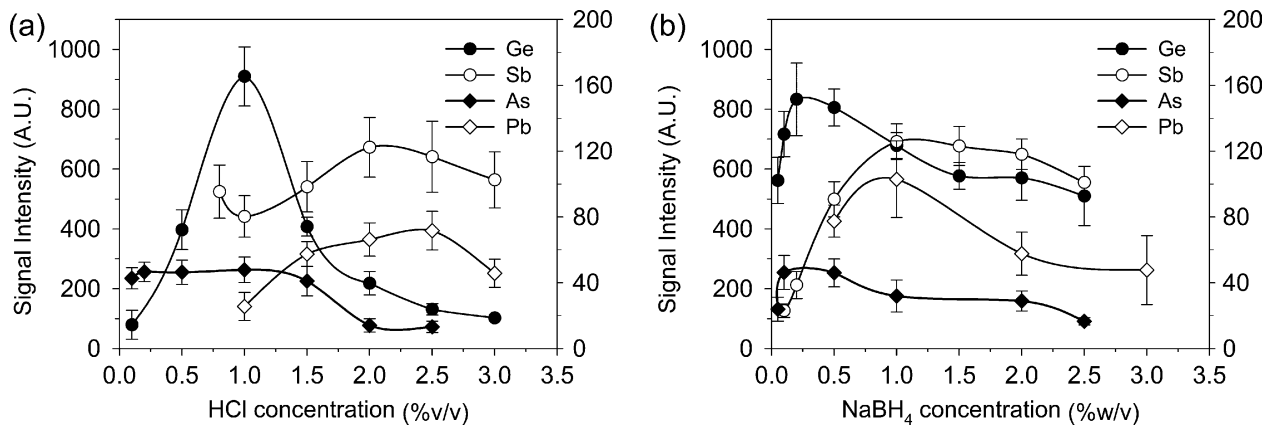

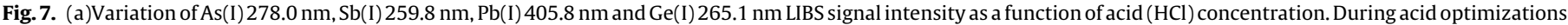

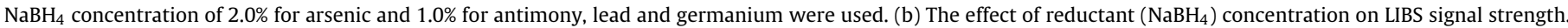
Left axis of the figures was used for Ge line intensity, and right axis was used for the representation of the $\mathrm{Sb}, \mathrm{As}$ and $\mathrm{Pb}$ signal.

decreases drastically and remains unchanged. Therefore, for lead determinations, optimum reductant concentration was selected as $1.0 \%$. Similarly, optimal sodium borohydride concentration that can produce maximum $\mathrm{Ge}(\mathrm{I})$ signal at $265.1 \mathrm{~nm}$ was obtained at $0.2 \%$.

\subsubsection{Effect of sample flow rate}

The acidified sample to the reductant flow rate was kept at a ratio of $1: 2$ by selecting an appropriate tubing size. Sample flow rate was adjusted to a desired flow rate by controlling pump rate. Three sample flow rate $1.0 \mathrm{~mL} \mathrm{~min}^{-1}, 2.5 \mathrm{~mL} \mathrm{~min}^{-1}$ and $4.0 \mathrm{~mL} \mathrm{~min}{ }^{-1}$ were studied. Fig. 8(a) shows the effect of sample flow rate on As, $\mathrm{Sb}, \mathrm{Pb}$ and $\mathrm{Ge}$ signal intensity. In order to present all elements on the same scale, Ge signal intensities were divided by ten.

Generally, increasing sample flow rate increases the signal strength, for each element studied, however, delivering the sample at a flow rate of $4.0 \mathrm{~mL} \mathrm{~min}^{-1}$ instead of $2.5 \mathrm{~mL} \mathrm{~min}^{-1}$ will result in condensation of arsine gas in the plasma cell and over consumption of sample and reagent. For Sb signal, no significant change was observed with the change in sample flow rate. Signal fluctuation remains within the range of error bars however; signal at $2.5 \mathrm{~mL} \mathrm{~min}^{-1}$ flow rate is slightly higher than 1.0 and $4.0 \mathrm{~mL} \mathrm{~min}^{-1}$ flow rates. Similarly, for both $\mathrm{Pb}$ and $\mathrm{Ge}$, maximum analyte response was observed at $2.5 \mathrm{~mL} \mathrm{~min}^{-1}$ sample flow rate. Therefore, $2.5 \mathrm{~mL} \mathrm{~min}^{-1}$ sample flow rate was selected as optimum for all elements studied.

\subsubsection{Carrier gas flow rate}

Although they are volatile, fast and efficient transport of hydrides from the reaction medium to the sample cell is necessary for obtaining highly sensitive measurements. Both, the type and the flow rate of the carrier gas have a significant influence on the signal strength. As discussed in Section 3.1, transportation of arsine, stibine and germane from GLS to sample/plasma cell was performed by using argon gas and for plumbane nitrogen gas was used. In order to study the effect of carrier gas flow rate, analyte signal from each element at their maximum emission wavelength was recorded as a function of carrier gas flow rates. The effect of carrier gas flow rate on $\mathrm{As}, \mathrm{Sb}, \mathrm{Pb}$ and Ge signal strength is shown in Fig. 8(b). Maximum sensitivities were obtained at $126 \mathrm{~mL} \mathrm{~min}^{-1}, 160 \mathrm{~mL} \mathrm{~min}^{-1}$ and $126 \mathrm{~mL} \mathrm{~min}^{-1} \mathrm{Ar}$ flow rates for $\mathrm{As}, \mathrm{Sb}$ and $\mathrm{Ge}$, respectively. For $\mathrm{Pb}(\mathrm{I})$, maximum signal was obtained at $155 \mathrm{~mL} \mathrm{~min}^{-1}$ flow rate of $\mathrm{N}_{2}$. Table 1 lists optimum conditions for all instrumental and chemical parameters studied.

\subsection{Calibration graphs and detection limits}

In order to determine the applicability of the HG-LIBS technique for quantitative analysis of $\mathrm{As}, \mathrm{Sb}, \mathrm{Pb}$ and $\mathrm{Ge}$ present in aqueous environments, calibration graphs were constructed, and detection limits were determined. Under optimal experimental and chemical conditions listed in Table 1, LIBS plasma emission from different analyte concentrations of a single element standards were used to
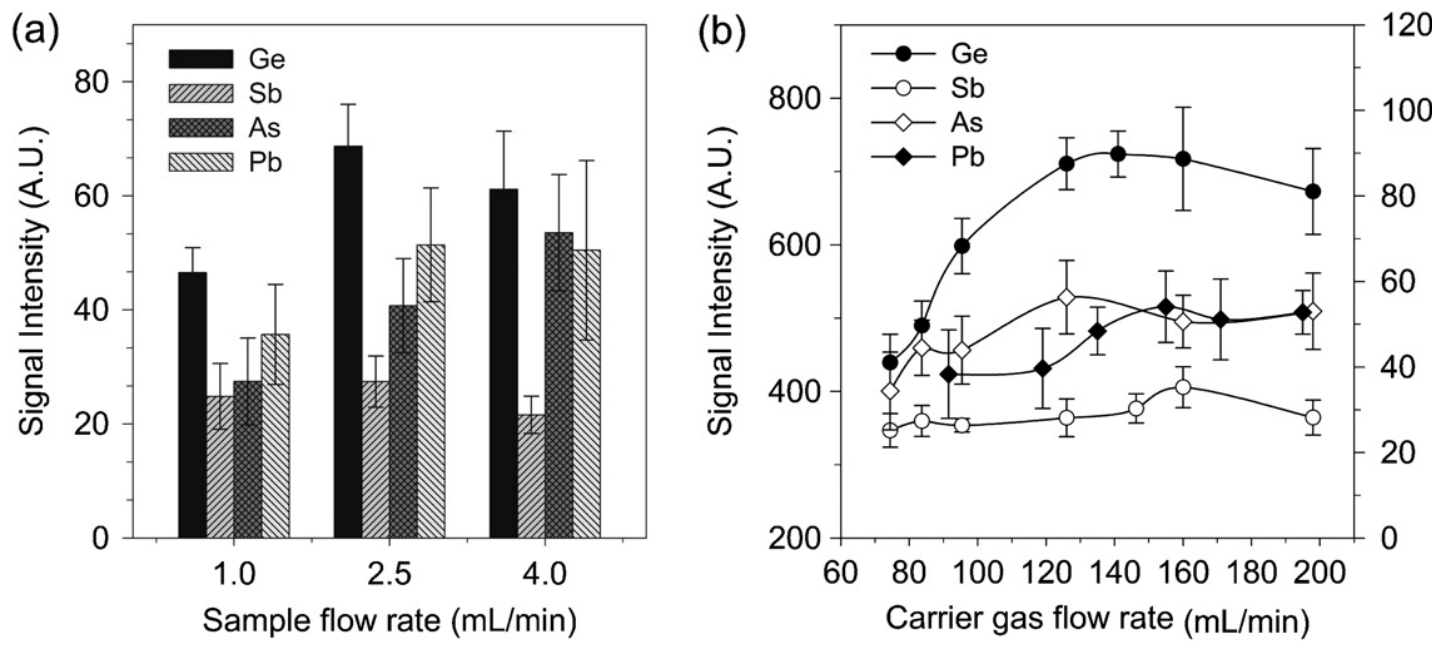

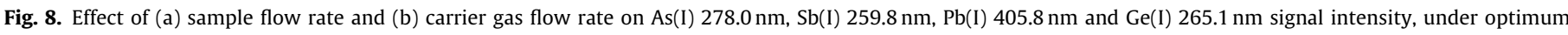
instrumental and chemical conditions of the HG-LIBS system. 
Table 1

Optimum instrumental and chemical conditions of HG-LIBS system and LOD values for $\mathrm{As}, \mathrm{Sb}, \mathrm{Pb}$ and $\mathrm{Ge}$ analysis.

\begin{tabular}{|c|c|c|c|c|}
\hline & As & $\mathrm{Sb}$ & $\mathrm{Pb}$ & $\mathrm{Ge}$ \\
\hline Spectral line (nm) & 278.0 & 259.8 & 405.8 & 265.1 \\
\hline Laser energy (mJ pulse ${ }^{-1}$ ) & 130 & 160 & 150 & 130 \\
\hline$t_{\mathrm{d}}(\mu \mathrm{s})$ & 3 & 2 & 5 & 1 \\
\hline$t_{\mathrm{g}}(\mu \mathrm{s})$ & 750 & 50 & 100 & 100 \\
\hline $\mathrm{NaBH}_{4}$ conc. $(\mathrm{w} / \mathrm{v}, \%)$ & 0.5 & 1.0 & 1.0 & 0.2 \\
\hline $\mathrm{NaBH}_{4}$ flow rate $\left(\mathrm{mL} \mathrm{min}^{-1}\right)$ & 5.0 & 5.0 & 5.0 & 5.0 \\
\hline $\mathrm{HCl}$ conc. (v/v, \%) & 1.0 & 2.0 & 2.5 & 1.0 \\
\hline Sample flow rate $\left(\mathrm{mL} \mathrm{min}^{-1}\right)$ & 2.5 & 2.5 & 2.5 & 2.5 \\
\hline $\begin{array}{l}\text { Pre-reducing/oxidizing agent conc. } \\
(\mathrm{w} / \mathrm{v}, \%)\end{array}$ & - & $0.5^{\mathrm{a}}$ & $2.0^{\mathrm{b}}$ & - \\
\hline Carrier gas flow rate $\left(\mathrm{mL} \mathrm{min}^{-1}\right)$ & 126 & 160 & 155 & 126 \\
\hline Limit of detection $\left(\mathrm{mg} \mathrm{L}^{-1}\right)$ & 1.1 & 1.0 & 1.3 & 0.2 \\
\hline
\end{tabular}

a $\mathrm{L}$-Cysteine was used as a pre-reducing agent.

b $\mathrm{K}_{3}\left[\mathrm{Fe}(\mathrm{CN})_{6}\right]$ was used as an oxidizing agent.

produce calibration graphs and are shown in Fig. 9(a)-(d). Measurements were performed at the most sensitive atomic emission lines of As (278.0 nm), Sb (259.8 nm), Pb (405.8 nm) and Ge (265.1 nm). Data points in graphs represent average of 10 replicate measurements each from the accumulation of 10 single laser shots and error bars are from the standard deviations of those measurements. As can be seen from the figure that, $\mathrm{As}, \mathrm{Sb}$ and $\mathrm{Pb}$ signal exhibit linear response with respect to analyte concentration and linear regression constants, $R^{2}$, are close to 0.99 for all. In the case of germanium, Fig. 9(d), the plot shows a deviation from linearity after $20.0 \mathrm{mg} \mathrm{L}^{-1}$ Ge concentration and regression constant value drops from 0.9978 to 0.9770 when the concentration range is extended to $50.0 \mathrm{mg} \mathrm{L}^{-1}$, indicating a loss of sensitivity at high concentrations.
This loss of sensitivity and hence deviation from linearity at high concentrations can be explained by self-absorption of resonance transition lines. In LIBS plasmas, self-absorption of the resonance lines is highly anticipated.

Detection limits calculated from the slopes of the calibration curves were based on $3 \sigma$ criterion, where $\sigma$ is the standard deviation of the background and LOD values of $1.1 \mathrm{mg} \mathrm{L}^{-1}, 1.0 \mathrm{mg} \mathrm{L}^{-1}$, $1.3 \mathrm{mg} \mathrm{L}^{-1}$ and $0.2 \mathrm{mg} \mathrm{L}^{-1}$ were obtained for $\mathrm{As}, \mathrm{Sb}, \mathrm{Pb}$ and $\mathrm{Ge}$, respectively.

Detection limits obtained for As, and $\mathrm{Sb}$ in this study are comparable with the ones in literature $[26,28]$ obtained by HG-LIBS method. A detection limit of $1.0 \mathrm{mg} \mathrm{L}^{-1}$ for As is reported by Singh et al., and LOD values of $0.7 \mathrm{mg} \mathrm{L}^{-1}$ for arsenic and $0.2 \mathrm{mg} \mathrm{L}^{-1}$ for antimony were reported by Simeonsson et al. Both results do not include optimization studies and are based on PMT type detection that could provide higher quantum efficiencies at the wavelengths of interest and larger detection area compared to ICCD type detectors.

To the best of our knowledge, there is no record in the literature based on HG-LIBS detection of $\mathrm{Pb}$ and $\mathrm{Ge}$, however, there are several reports on the determination of $\mathrm{Pb}$ in aqueous solutions based on direct liquids analysis by LIBS. Detection limits of $40 \mathrm{mg} \mathrm{L}^{-1}$ [6], and $100 \mathrm{mg} \mathrm{L}^{-1} \mathrm{~Pb}$ [14] were reported for experiments on liquid-jet and in bulk water analysis, respectively. In our previous work [25], a detection limit of $13.6 \mathrm{mg} \mathrm{L}^{-1} \mathrm{~Pb}$ was obtained from a LIBS system that utilize an ultrasonic nebulizer to produce sub-micron size aerosols. An LOD value of $1.3 \mathrm{mg} \mathrm{L}^{-1} \mathrm{~Pb}$ obtained in this study by the HG-LIBS technique, presents 10 times enhancement compared to that of by ultrasonic nebulization sample introduction system. Result also shows 30 and 77 times enhancement in LOD values compared to direct analysis of liquid samples by LIBS on liquid-jet and
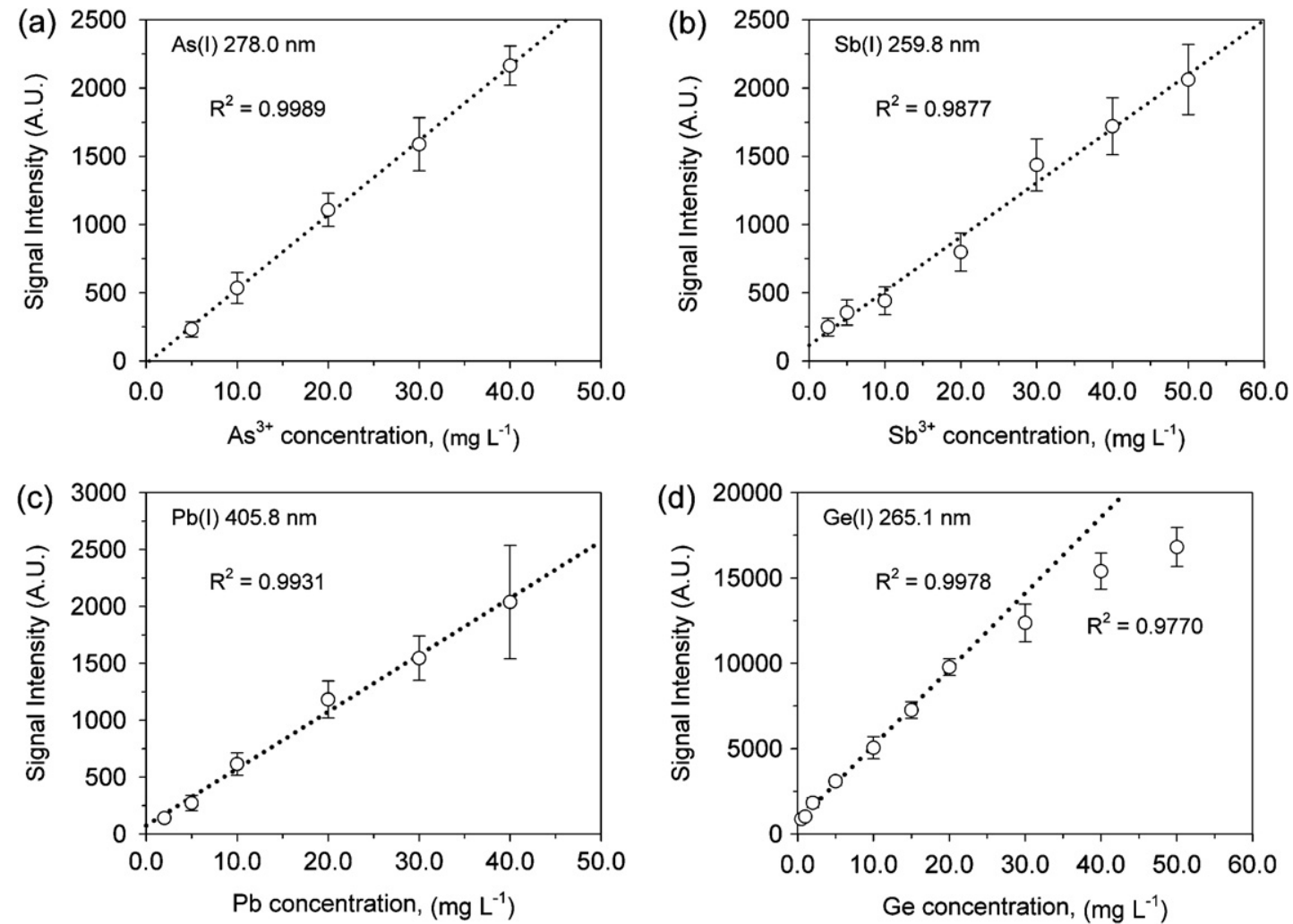

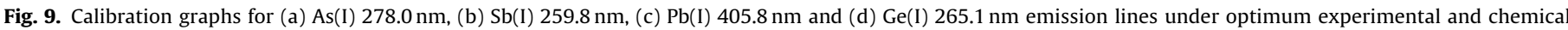

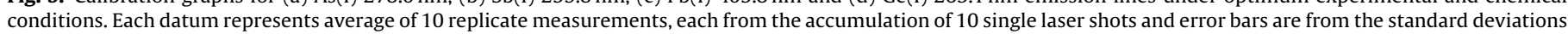
of those measurements. 
Table 2

Recovery results from the real water samples spiked with a single element standard solutions.

\begin{tabular}{|c|c|c|c|c|}
\hline & \multicolumn{4}{|l|}{$\%$ recovery \pm SD } \\
\hline & As & $\mathrm{Sb}$ & $\mathrm{Pb}$ & $\mathrm{Ge}$ \\
\hline River water, SLRS-4 & $80.9 \pm 12.9$ & $98.3 \pm 14.6$ & $128.9 \pm 18.9$ & $100.3 \pm 9.5$ \\
\hline Tap water, Urla municipal water & $84.2 \pm 4.0$ & $98.9 \pm 15.3$ & $129.7 \pm 11.1$ & $90.5 \pm 13.5$ \\
\hline Drinking water, spring water, Aydın & $100.9 \pm 19.4$ & $100.1 \pm 10.8$ & $108.9 \pm 15.6$ & $123.9 \pm 7.8$ \\
\hline
\end{tabular}

No detectable As, Sb, Pb and Ge signal before spiking by HG-LIBS system. $5 \mathrm{mg} \mathrm{L}^{-1} \mathrm{Ge}$ and $10 \mathrm{mg} \mathrm{L}^{-1} \mathrm{As}$, Sb and $\mathrm{Pb}$ were used for spiking real water samples.

in bulk water, respectively. Results are promising in terms of the applicability of the HG-LIBS technique to quantitative analysis of toxic elements.

\subsection{Application to real water samples}

In order to validate HG-LIBS method for quantitative analysis of $\mathrm{As}, \mathrm{Sb}, \mathrm{Pb}$ and $\mathrm{Ge}$ in environmental water samples, River Water Reference Material for trace metals, SLRS-4, tap water from the local laboratory and drinking water provided from a local market, were analyzed for $\mathrm{As}, \mathrm{Sb}, \mathrm{Pb}$, and $\mathrm{Ge}$ content. The concentrations of elements present in real water samples are at $\mu \mathrm{gL}^{-1}(\mathrm{ppb})$ level, which are below the detection limit of the HG-LIBS method. Therefore, water samples were ingested (spiked) with single standard solutions of $5 \mathrm{mg} \mathrm{L}^{-1}$ concentration for Ge and $10 \mathrm{mg} \mathrm{L}^{-1}$ concentration for $\mathrm{As}, \mathrm{Sb}$ and $\mathrm{Pb}$ to achieve desired final concentration. Then, the analyte content was determined under optimum chemical and experimental conditions, and recoveries were calculated.

Percent recovery results obtained from the average of 10 replicate measurements are given in Table 2. In general, for all types of water samples, recovery values within $\pm 20 \%$ standard deviation were obtained. Sb was among the best, with recoveries higher than $98 \%$. Arsenic presents recoveries higher than $80 \%$ for all water samples studied. For lead, higher than $100 \%$ recoveries obtained for all types of water samples could be due to non-equilibrated reaction medium from the addition of $\mathrm{K}_{3}\left[\mathrm{Fe}(\mathrm{CN})_{6}\right]$, since standards and samples were prepared at the same time and the calibration standards were analyzed prior to the samples. Therefore, samples have more time for the reaction to be completed. Germanium has shown recoveries of $100.3 \%$ and $90.5 \%$ and $123.9 \%$ for river, tap and drinking water, respectively.

The precision of laser-induced plasma measurements depends largely on shot to shot reproducibility of the laser pulses, however, homogeneity and complexity of the sample has also considerable influence on the formation and evolution of the plasma and its dynamics. LIBS technique usually has low precision and accuracy with a typical RSD value in the range of $5-10 \%$. Relatively worse precision values obtained from this work could be attributed to inhomogeneity of the plasma and possible matrix effect through chemical hydride generation process, which could be a subject to a more detailed study. Further investigations on the interference effect from the presence of other hydride forming elements will provide additional insights into the applicability of the HG-LIBS technique for the routine analysis of toxic elements in aqueous samples.

\section{Conclusion}

A systematic study on optimization of instrumental and chemical parameters of a HG-LIBS system was performed for the first time, in an attempt to analyze arsenic, antimony, lead and germanium in environmental water samples. Results showed that, HG-LIBS signal is significantly affected by the type of the ambient gas. Strong enhancement observed in argon atmosphere for As, $\mathrm{Sb}$ and Ge lines may be attributed to the Penning ionization effect in which metastable Ar atoms contribute to the establishment of a state of sustained emission of analyte atoms in HG-LIBS plasmas.

HG-LIBS technique described here is applicable to the direct and continuous analysis of water samples at low $\mathrm{mg} \mathrm{L}^{-1}$ concentrations. Under optimum experimental conditions, detection limits of $1.1 \mathrm{mg} \mathrm{L}^{-1}$ for As, $1.0 \mathrm{mg} \mathrm{L}^{-1}$ for $\mathrm{Sb}, 1.3 \mathrm{mg} \mathrm{L}^{-1}$ for $\mathrm{Pb}$ and $0.2 \mathrm{mg} \mathrm{L}^{-1}$ for Ge were obtained. Detection limits obtained in this study are still higher than other conventional atomic spectrometric techniques (AAS, ICP-OES), that utilize hydride generation sample introduction method, however, entirely different atomization and excitation dynamics of laser-produced plasmas make a direct comparison of the analytical figures of merits difficult.

In this study, HG-LIBS technique has shown up to 77 times improvement in LOD for $\mathrm{Pb}$, compared to literature value obtained by direct LIBS analysis of bulk liquid samples. Further enhancements may be achieved by using double-pulse LIBS technique.

HG-LIBS technique has been applied to the analysis of real water samples from spiking experiments, and recovery values higher than $80 \%$ were obtained for all types of water samples. Considering some inherent advantages of the LIBS technique, like its speed, ability to identify all elements in situ, with a single laser pulse, the proposed approach can be useful for the development of a portable LIBS sensor for the diagnosis and monitoring of environmental pollutants.

\section{Acknowledgments}

The authors thank the Izmir Institute of Technology, IYTE and the Scientific and Technological Research Council of Turkey, TÜBiTAK, for their financial support through research projects: BAP-12 and $109 \mathrm{~T} 327$.

\section{References}

[1] L.J. Radziemski, D.A. Cremers, Laser-Induced Plasmas and Applications, Marcel Dekker, New York, 1989.

[2] A.W. Miziolek, V. Palleschi, I. Schechter (Eds.), Laser-Induced Breakdown Spectroscopy: Fundamentals and Applications, Cambridge University Press, New York, 2006.

[3] C. Lopez-Moreno, S. Palanco, J.J. Laserna, F. DeLucia Jr., A.W. Miziolek, J. Rose, R.A. Walters, A.I. Whitehouse, J. Anal. At. Spectrom. 21 (2006) 55-60.

[4] L. St-Onge, M. Sabsabi, P. Cielo, Spectrochim. Acta B 53 (1998) 407-415.

[5] R.J. Lasheras, C. Bello-Gálvez, E.M. Rodríguez-Celis, J. Anzano, J. Hazard. Mater. 192 (2011) 704-713.

[6] O. Samek, D.C.S. Beddows, J. Kaiser, S.V. Kukhlevsky, M. Liška, H.H. Telle, J. Young, Opt. Eng. 39 (2000) 2248.

[7] S. Koch, W. Garen, M. Müller, W. Neu, Appl. Phys. A: Mater. 79 (2004) 1071-1073.

[8] E. Cheng, R. Fraser, J. Eden, Appl. Spectrosc. 45 (1991) 949-952.

[9] L. Dudragne Ph., A.J. Amouroux, Appl. Spectrosc. 52 (1998) 1321-1327.

[10] E.M. Cahoon, J.R. Almirall, Anal. Chem. 84 (2012) 2239-2244.

[11] M.E. Asgill, D.W. Hahn, Spectrochim. Acta B 64 (2009) 1153-1158.

[12] N.K. Rai, A. Rai, J. Hazard. Mater. 150 (2008) 835-838.

[13] S.L. Lui, Y. Godwal, M.T. Taschuk, Y.Y. Tsui, R. Fedosejevs, Anal. Chem. 80 (2008) 1995-2000.

[14] P. Fichet, P. Mauchien, J.F. Wagner, C. Moulin, Anal. Chim. Acta 429 (2001) 269-278.

[15] J. Gruber, J. Heitz, H. Strasser, D. Bäuerle, N. Ramaseder, Spectrochim. Acta B 56 (2001) 685-693.

[16] S. Groh, P.K. Diwakar, C.C. Garcia, A. Murtazin, D.W. Hahn, K. Niemax, Anal. Chem. 82 (2010) 2568-2573.

[17] S. Koch, R. Court, W. Garen, W. Neu, R. Reuter, Spectrochim. Acta B 60 (2005) 1230-1235.

[18] V.S. Burakov, N.V. Tarasenko, M.I. Nedelko, V.A. Kononov, N.N. Vasilev, S.N. Isakov, Spectrochim. Acta B 64 (2009) 141-146. 
[19] J.L. Gottfried, F.C. De Lucia Jr., C.A. Munson, A.W. Miziolek, Spectrochim. Acta B 62 (2007) 1405-1411.

[20] K. Rifai, S. Laville, F. Vidal, M. Sabsabi, M. Chaker, J. Anal. At. Spectrom. 27 (2012) $276-283$.

[21] A. De Giacomo, M. Dell'Aglio, F. Colao, R. Fantoni, V. Lazic, Appl. Surf. Sci. 247 (2005) 157-162.

[22] J.-S. Huang, H.-T. Liu, K.-C. Lin, Anal. Chim. Acta 581 (2007) 303-308.

[23] J.S. Huang, K.C. Lin, J. Anal. At. Spectrom. 20 (2005) 53-59.

[24] P. Diwakar, P. Jackson, D. Hahn, Spectrochim. Acta B 62 (2007) 1466-1474.

[25] N. Aras, S. Ünal Yeșiller, D. Arıca Ateș, S. Yalcin, Spectrochim. Acta B 74-75 (2012) 87-94.

[26] J. Dedina, D. Tsalev, Hydride Generation Atomic Absorption Spectrometry, Wiley and Sons, New York, 1995.

[27] J.P. Singh, H. Zhang, F.Y. Yueh, K.P. Carney, Appl. Spectrosc. 50 (1996) 764-773.

[28] S. Ünal, S. Yalçın, Spectrochim. Acta B 65 (2010) 750-757.

[29] J. Simeonsson, L. Williamson, Spectrochim. Acta B 66 (2011) 754-760.

[30] F. Garrelie, C. Champeaux, A. Catherinot, Appl. Phys. A 69 (Suppl.) (1999) S55-S58.

[31] J.A. Aguilera, C. Aragon, Appl. Phys. A 69 (Suppl.) (1999) S475-S478.

[32] B. Salle, D.A. Cremers, S. Maurice, R.C. Wiens, Spectrochim. Acta B 60 (2005) 479-490.
[33] K. Kagawa, M. Ohtani, S. Yokoi, S. Nakajima, Spectrochim. Acta B 39 (1984) 525-536.

[34] S.S. Bindhu, Harilal C.V., V.P.N. Nampoori, C.P.G. Vallabhan, Appl. Phys. Lett. 72 (2) (1998) 167-169.

[35] Y. Lida, Appl. Spectrosc. 43 (1989) 229-234.

[36] Y. Lida, Spectrochim. Acta B 45 (1990) 1353-1367.

[37] Y. Sasaki, K. Wagatsuma, Anal. Sci. 25 (2009) 481-485.

[38] C.A. Henry, P.K. Diwakar, D.W. Hahn, Spectrochim. Acta B 62 (2007) 1390-1398.

[39] Z.S. Lie, H. Niki, K. Kagawa, May On Tjia, R. Hedwig, M. Pardede, E. Jobiliong, M.M. Suliyanti, S.N. Abdulmadjid, K.H. Kurniawan, J. Appl. Phys. 109 (2011) 103305.

[40] H.R. Griem, Plasma Spectroscopy, McGraw-Hill, New York, 1964.

[41] B. Welz, M. Sucmanova, Analyst 118 (1993) 1417-1423.

[42] A. D’Ulivo, L. Lampugnani, G. Pellegrini, R. Zamboni, J. Anal. At. Spectrom. 10 (1995) 969-974.

[43] A. D'Ulivo, M. Onor, R. Spiniello, E. Pitzalis, Spectrochim. Acta B 63 (2008) $835-842$.

[44] J. Tyson, R. Ellis, G. Carnrick, F. Fernandez, Talanta 52 (2000) 403-410.

[45] I.D. Brindle, R. McLaughlin, N. Tangtreamjitmun, Spectrochim. Acta B 53 (1998) 1121-1129. 